\title{
Improving utilization and awareness of Family Planning services in adults of Reproductive age through Community sensitization in police wing village, Jinja District.
}

\author{
Henry Rodgers Isiko ${ }^{a}, 1,2$, Charles Kato ${ }^{a}$, Jeremiah Okumua , Mariam \\ Babita ${ }^{a}$, Jacob Kumakech ${ }^{a}$, Mercy Faith Lakisaa , Hamza Isabiryea, \\ Shanny Nambubaa
}

a College of Health Sciences, Makerere Univeristy, Uganda

Abstract

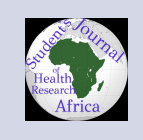

Background $^{a}$

Family planning refers to a conscious effort by a couple to space the number of children they have through the use of contraceptive methods. According to WHO, an estimated 225 million women in developing countries, $24.2 \%$ of women of reproductive age have an unmet need for contraception. However, contraceptive use in sub-Saharan Africa is low at only $21 \%$. The total fertility rate remains high for many countries in the region (4.6 in Kenya and Rwanda, 5.4 in Tanzania, 6.2 in Uganda, and 6.4 for Burundi).

\section{Methodology}

This was a community-based project implementation on increasing awareness and utilization of family planning methods in Police Wing village, Jinja district. Consent was gotten from the VHT, LC1, and DHO before mobilizing people to gather at the VHT's home and her neighbour's compound where we carried out the different educational sessions. Different team members got different roles to play as regards the health education session.

One week later, we evaluated the progress of our project implementation through the administration of questionnaires to the same people we health educated. The questionnaire assessed the level of utilization, awareness, myths, misconception, and demography of the participants.

$28 \%$ had heard about at least three family planning methods and $24.1 \%$ had at one time used family planning while $75.9 \%$ of the participants admitted not to have used it. The post-session assessment showed an increase from $28 \%$ to $93 \%$ in knowledge regarding the available methods of FP and an increase in the utilization of FP from $28 \%$ to $42 \%$.

Results

$28 \%$ had heard about at least three family planning methods and $24.1 \%$ had at one time used family planning while $75.9 \%$ of the participants admitted not to have used it. The post-session assessment showed an increase from $28 \%$ to $93 \%$ in knowledge regarding the available methods of FP and an increase in the utilization of FP from $28 \%$ to $42 \%$.

\section{Conclusion and recommendations}

Addressing the myths and misconceptions about FP by exposing them as a fallacy would help increase the uptake as evidenced by the will of the community to take up the different methods. Organize frequent health talks about FP in the community. 


\section{Background:}

Family planning refers to a conscious effort by a couple to limit or space the number of children they have through the use of contraceptive methods. (UBOS, 2016). According to All answers Ltd (2018), Contraceptive methods are classified as modern or traditional methods. Modern methods include female sterilization, male sterilization, the pill, the intrauterine, contraceptive device (IUD), implants, injectable, male condoms, female condoms, emergency contraception, standard days method (SDM). A method such as withdrawal and calendar method or rhythm method are considered traditional (UBOS, 2016).

An estimated 225 million women in developing countries would like to delay or stop childbearing but are not using any method of contraception. Reasons for this include; Limited choice of methods, limited access to contraception, particularly among young people, poorer segments of populations or unmarried people, Fear of experiencing side effects, Cultural or religious opposition, poor quality of available services, Users and providers bias, Gender-based barriers.

Family planning is widely acknowledged as an important intervention towards achieving sustainable development goals (SDGs) as it has proven to reduce maternal and child mortality. It is stipulated in goal 3 that involves good health and wellbeing since half of the women in developing countries have received the health care they need and the need for family planning has increased exponentially while the need met is growing slowly.

Section 3.1 aims at reducing the global maternal mortality ratio to less than 70 per 100000 live births and section 3.2 to reduce the infant mortality rate by a third by 2030 which goals can also be achieved through proper family planning.

Section 3.7 aims at ensuring universal access to sexual and reproductive healthcare services, including family planning information and education and the integration of reproductive health into the national strategies and programs.

The unmet need for contraception remains too high. The inequity is fuelled by both a growing population and a shortage of family planning services. In Africa, $24.2 \%$ of women of reproductive age have an unmet need for modern contraception. (UNDESA, 2015)
Fertility and future projected population growth is much higher in sub-Saharan Africa than in any other region of the world (John et al., 2010).

Concerns that uncontrolled population growth will hinder the attainment of development and health goals in our communities leads to the present study which rests on the assumption that fertility will decline only if the population at large adopt effective modern methods of contraception as witnessed in other parts of the world

However, contraceptive use in sub-Saharan Africa is low at only $21 \%$, mainly as a result of inaccessibility to contraceptive methods (United Nations, 2006; Hubacher et al., 2008)

The total fertility rate remains high for many countries in East Africa (4.6 in Kenya and Rwanda, 5.4 in Tanzania, 6.2 in Uganda, and 6.4 for Burundi); Modern contraceptive prevalence in the eastern African region is generally low and with a wide range of disparity $(17.7 \%$ in Burundi to $45.1 \%$ in Rwanda). The contraceptive prevalence rate is low due to inadequate access to information, education and Counseling, FP commodity, staff availability, skills, social and cultural factors. The levels of unmet need for family planning are generally higher than contraceptive use in most countries in eastern Africa. In most DHS reports, Injectables, and pills are the most popular methods, with low utilization of condoms, implants, and IUDs. The use of condoms and IUDs is plagued by numerous myths and misconceptions both amongst health workers and the general population. (Eliason S et al., 2013).

Uganda has one of the highest fertility rates worldwide a woman from Uganda would bear an average of 5.8 children in her life most of whom admit having nearly two or more children than they want, birth intervals remain short, and Ugandan women have more than three children by their late 20s. Recent statistics, which reveal that the number of women of reproductive age using contraception in Uganda is the only 28percent, thus contributing to an increase in the number of unwanted pregnancies. (UBOS,2016).

The paradox is that two in every five women in Uganda want to space or limit childbirth, but are not using contraceptives hence have an unmet need for family planning. (Khan et al., 2008). The unmet need for contraceptive use is, therefore, two to three times higher than the current use of contraceptives 
Family planning is thus being looked at as the best solution to ensuring a better and healthier population in Uganda given that the country's population is growing at $3.4 \%$, the second-highest in the world, while the resources to cater to the population are constant. The total population according to the 2014 census is 34.6 million people with $51 \%$ females and population density is at 173 persons per square kilometer. Children below 18 years make up 55\% of the population. The population in Jinja district had also increased from 387,573 in 2002 to 471,242 in 2014 while resources continue being scarce. (UBOS, 2016)

The full implementation of the Uganda Family Planning Costed Implementation Plan, 2015-2020 (FP-CIP) by the GOU and partners will enable Uganda to reach these ambitious goals.

Strategic priorities were identified to ensure that the current gaps in family planning in Uganda are adequately addressed:

Priority 1: Increase age-appropriate information, access, and use of family planning amongst young people, ages 10-24 years

Priority 2: Promote and nurture change in social and individual behaviour to address myths, misconceptions, and side effects and improve acceptance and continued use of family planning to prevent unintended pregnancies

Priority 3: Implement task sharing to increase access, especially for a rural and underserved population.

Priority 4: Mainstream implementation of family planning policy, interventions, and delivery of services in multi-sectoral domains to facilitate a holistic contribution to social and economic transformation Priority 5: Improve forecasting, procurement, and distribution and ensure full financing for commodity security in the public and private sectors.

Uganda's goal of reaching 50 percent of women who are married or in union with modern contraceptive methods is ambitious and must be matched commensurate support in the areas of human resources, financing, and political commitment from national to community levels throughout the country. (MoH, 2014)

There is little awareness and utilization of family planning methods amongst adults of reproductive age in the Police wing village.

From our community diagnosis report carried in 2016 in Walukuba east, $62 \%$ of the households 4-6 people, and $28 \%$ having more than 6 people. There were 270 households with a population of 1352 people. $68 \%$ of the adults of reproductive age said they do not use family planning methods while $32 \%$ use.

There are many reasons why women do not use contraceptives in police wing villages, Walukuba east parish e.g. lack of access to family planning services (15\%) and information is often a barrier (57\%). Male partners also influence women negatively in practice contraception (5\%). Some people have both cultural and religious beliefs about family planning that need rectification (10\%). Other people believe that family planning can cause health problems like infertility and cancer, while others felt that contraceptive use might cause women to have extramarital affairs (3\%), the rest have other reasons (10\%). Therefore, we decided to implement this project to overcome all these problems.

\section{Methodology}

\section{Project Site}

This was a community-based project, in Police wing village, Walukuba east parish, Masese division in Jinja district. Jinja district is situated on the northern shore of Lake Victoria, overlooking the Napoleon Gulf, which constitutes the source of the Nile River. It is $80 \mathrm{~km}$ (50 Miles) from Kampala along the Kampala-Tororo highway (JMC, 1994). The coordinates of Jinja, Uganda is latitude: $0027 \mathrm{~N}$; longitude: $03311 \mathrm{E}$.

Walukuba East parish has 6 villages that include: Central village, School village, Church village, Ntege village, Steel/Ufro village, and Police Wing village.

The nearest place for seeking health services by the community members is Walukuba Health Centre IV which doesn't conduct community outreaches to enhance the utilization of family planning services in the community.

\section{Target Population}

Adults of reproductive age (15-49 years for females and males of 15 years and above). There are 322 adults of reproductive age of which 179 are females and 143 are males.

Materials we used to carry out the activity include;

Family planning flip Charts from the ministry of health, Markers, Dummy penis, Manilla paper, Samples of family planning methods e g condoms, oral 
contraceptives, IUD, Implant, Depo-Provera, moon beads

These were provided by Walukuba Health Centre IV and the JRRH family planning unit.

\section{Implementation}

We had a pre-visit to the community to meet the VHT and $\mathrm{LCl}$ chairlady to inform them about our project in the community on Monday 10th July 2017. This was done by all the students.

On this same day, we asked the VHT and LC1 to do a door to door mobilization of the community which she carried out along with us and the organization of venue where we held two sessions on two different days to implement our intervention which was done on Wednesday and Thursday of the first week. We facilitated them in doing this by funding their lunch, airtime, and transport. We held the activity (education sessions) at the VHT's place and the neighbour's compound.

At the community gathering, we organized a pre-test as the participants arrived at the venue. After registration, we had one person (kumakech) guiding the people and sending them to the interviewers at any of the seven different groups we had set up. Each group had one student/group member (implementers) each having a similar copy of the questionnaire to administer. Each questionnaire was administered for about one minute and assessed both demographic and awareness plus the utilization of different family planning methods.

The VHT introduced us to the community members who had gathered. We then conducted the health education with Babita Mariam giving a brief introduction to the group members and she also introduced our project (about family planning), what it is, its importance, and its utilization in Uganda, various affordable methods and advantages of family planning. Henry Isiko addressed the myths and misconception as he educated the community that such are not true and assured them of the safety and effectiveness of family planning. He also educated them on the advantages and disadvantages of condom use. Isabirye Hamza educated on IUDs; how to use IUD, their advantages and disadvantage, and their side effects. Okumu Jeremiah talked about injecta-plan (depo-provera) and all its advantages and disadvantages compared to using other methods. Kato Charles Showed them the pills (POP and COCs) and educated them about oral contraceptives; the dosage, advantages, and side effects compared to other methods. Nam- buba shanny talked about implants; the different brands available, duration of action, advantages, disadvantages, and side effects, and what to do in case of side effects. Lakisa Mercy Faith talked about natural methods such as moon beads. Kumakech Jacob summarized all methods of family planning in the Luo language to educate the community members/participant who was Luo (Acholi, Langi, and Alur) who did not understand the session well as they were being given in Lusoga. Babita Mariam then demonstrated how to use a male condom according to CDC guidelines using a dummy penis.

Each presenter had roughly seven minutes to present his or her part in that not much time is spent explaining as this would divert people's attention as they would feel exhausted easily.

Finally, we distributed condoms and oral contraceptives which we had to the participant, the remaining condoms we left with the VHT who would serve them out.

We demonstrated using family planning flip charts that contain the different methods and their use based on the ministry of health. The audience was given chance to ask a question about family planning for clarification on what they had not understood well and were answered accordingly.

We then had the second session on Thursday $13 / 07 / 2017$ and the process was similar to the one above.

\section{Project Evaluation}

This involved data collection using questionnaires and interviews. Questionnaires were administered at the household level. Our target population was the community members (adults of reproductive age) who were present during the intervention session.

We included at least 102 of the adults who participated in the intervention as chosen from the list of the attendance. All people involved in the evaluation of our project were females. This was done alongside the $\mathrm{VHT}$ and the group members in pairs.

Members were traced using the phone numbers they registered on the attendance list.

\section{Inclusion Criteria}

All adults of reproductive age who consented and were part of the project implementation were included, women who are $15 y$ years to 45 years and men 15 years and above.

\section{Exclusion Criteria}


Young, drunkards, mentally ill individuals are not included and those who refuse to consent and take part in the project implementation.

\section{Parameters evaluated and how.}

We carried out our project evaluation in two days. The first, one week after our last intervention (Thursday 20th) and the second evaluation on the following day (Friday 21 st) Here we gave them the same questionnaire used before the sessions on the days of implementation. We then analyzed the results of the pre-test and post-test.

We involved everyone who registered during the intervention phase though we managed to only get 102 as the others were not present. Here we then assessed whether some had started using Family planning, their knowledge about the different methods, willingness to start using family planning, and how they thought family planning would affect their lives.

\section{Ethical Consideration}

First, we received approval to conduct our project implementation from the district health officer (DHO), LC1 chairperson of police wing village, and the Village health team.

Verbal consent was sought from each participant after explaining to them that involvement in the project was voluntary and the benefits to be acquired from taking part in the project. A high level of confidentiality of the information collected during the project was maintained

\section{Data analysis and interpretation}

\section{Data organization}

We organized data from the questionnaires into summaries by tallying the different options

The results were then put in different groups based on different ranges of values.

\section{Data presentation}

The summarized data were presented using the following techniques; tables, bar graphs, and pie chart

\section{Data interpretation}

The data was interpreted by studying and explaining the trends of the results presented and the differences between the pre and post-intervention results.

\section{Quality assurance}

During the Pre-testing of our tools, we evaluated how best our interview guide and questionnaire would be able to generate for us the results. We did this at JRRH where we gave the questionnaires and interviews to a few people at the facility.

In the community, during the implementation, we used the same question before and after the education.

We only included those who were present during the intervention in the evaluation process.

\section{Results}

A total of 108 adults of reproductive age in the community turned up for the two sessions we held in the police wing village during the implementation of our project.

During the sessions, interviewer-administered questionnaires were used to collect data on knowledge about family planning from the 108 members who came before the education session was conducted. We then went for a post-implementation assessment to evaluate the progress of the intervention. We administered questionnaires to 102 adults of the total participants (108 adults). The questionnaire results for the pre and postimplementation assessment of our project on family planning are as shown below;

\section{Sex of the participants}

Of the 108 participants, there were 107 females and only 1 male

\section{Participants age}

The majority of participants were between 21 to 30 years (33.3\%), 30.5\% of the participants were 31 to 40 years, $22.3 \%$ were 41 to 50 years while $13.9 \%$ of the participants were 15 to 20 years old.

$$
\mathrm{N}=108
$$

\section{Level of education of participants}

Most participants, 59.2\% attained secondary education, $29.6 \%$ primary level, those with tertiary level of education were $8.3 \%$ while $2.9 \%$ reported not having had any formal education.

$$
\mathrm{N}=108
$$

\section{Religion of participants}

Most participants were catholics followed by born-again, the Anglican and moslems, while some small groups belonged to other religions such as pentecostal and seventh day adventist

\section{Marital status of participants.}

Most participants were married (75.9\%), while $12.9 \%$ were single where as $7.4 \%$ and $3.8 \%$ respectively were divorced and widowed respectively.

\section{Number of children participant.}




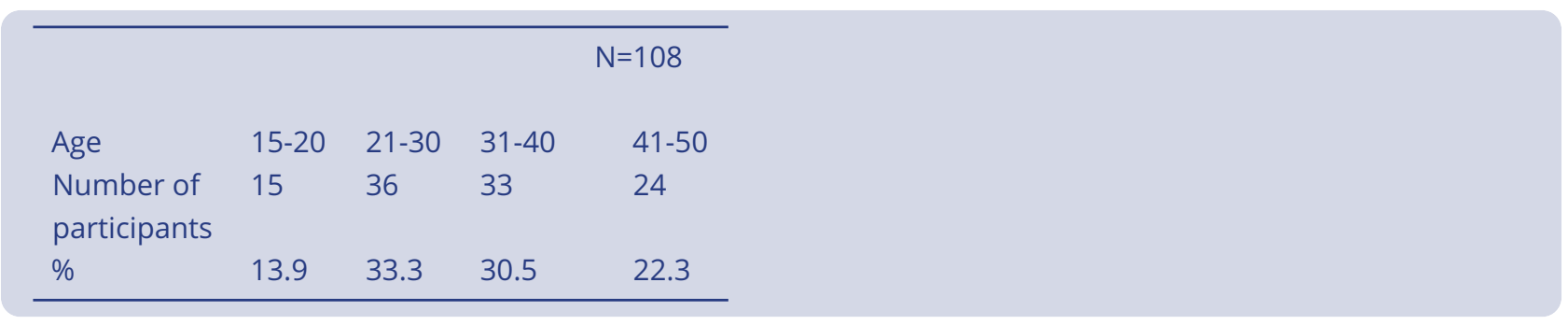

Table 1. Level of education of participants

\begin{tabular}{lllll}
\hline & & \multicolumn{5}{c}{$\mathrm{N}=108$} \\
Level & Primary & Secondary & Tertiary & None \\
No of people & 32 & 64 & 9 & 3 \\
percentage & 29.6 & 59.2 & 8.3 & 2.9 \\
\hline
\end{tabular}

Table 2. Religion of participants

\begin{tabular}{|c|c|c|c|c|c|}
\hline & & & & $N=108$ & \\
\hline Religion & Catholics & Anglican & Moslem & Born-again & Others \\
\hline $\begin{array}{l}\text { Number of } \\
\text { people }\end{array}$ & 35 & 22 & 17 & 24 & 10 \\
\hline Percentage & 32.4 & 20.4 & 15.7 & 22.2 & 9.3 \\
\hline
\end{tabular}

Table 3. Marital status of participants

\begin{tabular}{lllll}
\hline & & \multicolumn{3}{c}{$\mathrm{N}=108$} \\
Marital status & Married & Single & Widowed & Divorced \\
$\begin{array}{l}\text { Number of } \\
\text { individual }\end{array}$ & 82 & 14 & 4 & 8 \\
percentage & 75.9 & 12.9 & $\begin{array}{l}3.8 \\
\text { N=108 }\end{array}$ & 7.4 \\
& & & $\mathrm{~N}$ & \\
\hline
\end{tabular}

94 of our total participants (108) were married/ out of marriage but with children. The number of children of the participants are as shown below.

\section{Knowledge about family planning among the participants}

The participants were assessed before and after the implementation for knowledge of at least three family planning methods and the result showed that before the assessment, only $28 \%$ had knowledge of at least three methods but one week after the implementation, $93 \%$ had knowledge of at least three methods pre-assessment knowlege about Family planning [VALUE]\%

Had knowledge about FP Ignorant about FP

\section{$\mathbf{7 2 \%}$}

\section{$\mathrm{N}=102$}

Participant's Knowledge about different family planning methods.

The table below shows the number of people with knowledge about the different family planning methods before the implementation

$$
\mathrm{N}=108 \mathrm{~N}=108 \mathrm{~N}=102
$$


Table 4. Number of children participant.

$$
\mathrm{N}=94
$$

Number of 1 to $2 \quad 3$ to $4 \quad 5$ to 6 Above 6

children

$\begin{array}{lllll}\text { percentage } & 10.6 & 35.1 & 45.7 & 8.6\end{array}$

Table 5. number of people with knowledge about the different family planning methods before the implementation

\begin{tabular}{|c|c|c|c|c|c|c|c|}
\hline $\begin{array}{l}\text { FP } \\
\text { methods }\end{array}$ & $\begin{array}{l}\text { Injections } \\
\text { (Depo) }\end{array}$ & $\begin{array}{l}\text { Pills (POPs and } \\
\text { COCs) }\end{array}$ & $\begin{array}{l}\text { con- } \\
\text { doms }\end{array}$ & IUDS & $\begin{array}{l}\text { im- } \\
\text { plants }\end{array}$ & $\begin{array}{l}\text { surgi- } \\
\text { cal }\end{array}$ & $\begin{array}{l}\text { Natural } \\
\text { methods }\end{array}$ \\
\hline $\begin{array}{l}\text { No of } \\
\text { people }\end{array}$ & 86 & 38 & 108 & 31 & 48 & 13 & 4 \\
\hline Percentage & 79.6 & 35.2 & 100 & 28.7 & 44.4 & 12.0 & 3.7 \\
\hline
\end{tabular}

\section{Utilization of FP services}

The table below shows the utilization of family planning among the participants in the community. Only 26 people were using family planning before the intervention but after the intervention, we registered significant increase of up to 42 people among our participant enrolled on different FP methods. This represented $24.1 \%$ and $41 \%$ respectively.

$$
\mathrm{N}=108
$$

$\mathrm{N}=108$

\section{Methods of FP they are using before the intervention was implemented}

$\mathrm{N}=26$

$\mathrm{N}=26$

Utilization of different family planning methods by the participant after the intervention

There was increased utilization after the implementation. The number of people using different methods increased including utilization of method such as IUDs which were not used before the intervention.

$\mathrm{N}=42$ Where the members get their FP services before our intervention.

$\mathrm{N}=26$

There was increased utilization of family planning services from Walukuba HCIV and JRRH after our project implementation as most people were made aware of the services available as compared to low utilization by the community from those facilities before the implementation.

\section{Reason Why some people do not use FP methods/myths and misconception about FP} $\mathrm{N}=108$

\section{Discussion:}

Low levels of awareness could be explained by little health education talks held in the village and the district at large. The nearest Walukuba health center IV is where such information can easily be assessed so unless someone goes to the hospital, such information cannot be availed. The poor health-seeking behavior amongst the community members especially the males may also contribute to poor access to information about family planning.

Generally, there was increased utilization of all family planning methods among the participant in the police wing village, Walukuba East in Jinja district. The initial low levels of utilization of all the methods may be explained by the misconceptions and poor attitude towards family planning. The poor attitude is explained by mainly religious biases and person-to-person pass down of wrong information about family planning among the community members.

The least used methods were pills (POPs and COCs), IUDs due partly to; lack of knowledge on 
Table 6. utilization of family planning among the participants in the community

\begin{tabular}{lll}
\hline & Using & Not using \\
Number of participants & 26 & 82 \\
Percentage & 24.1 & 65.9 \\
\hline
\end{tabular}

Table 7. Methods of FP they are using before the intervention was implemented

\begin{tabular}{llllll}
\hline Method of FP & Injection (Depo) & Implant & Pills (POP and COC) & IUDS & Condoms \\
Number of people & 11 & 9 & 3 & 2 & 1 \\
Percentage & 42.3 & 34.6 & 11.5 & 7.7 & 3.9 \\
\hline
\end{tabular}

Table 8. Utilization of different family planning methods by the participant after the intervention

\begin{tabular}{llllll}
\hline FP method & Injection(Depo) & Implants & Pills(POP and COC) & Condoms & IUDS \\
Number of people & 14 & 11 & 3 & 6 & 8 \\
Percentages & 33.3 & 26.2 & 7.1 & 14.3 & 19.1 \\
\hline
\end{tabular}

Table 9. Where the members gettheir FP services before our intervention

\begin{tabular}{llll}
\hline Places where participants get FP services & Private clinics & Walukuba HC IV & Pharmacy \\
Number of people & 16 & 6 & 4 \\
percentage & 61.5 & 23.1 & 15.4 \\
\hline
\end{tabular}

Table 10. Reason Why somepeople do not use FP methods/myths and misconception about FP

\begin{tabular}{ll}
\hline Barriers & Number of people \\
Causes cancer & 92 \\
Cause infertility & 80 \\
Causes birth defects & 71 \\
Makes women lose sexual desire(libido) & 10 \\
Husband prevents their wife & 17 \\
Interfere with nature & 23 \\
Religion & 28 \\
Limited access to FP services & 53 \\
\hline
\end{tabular}

these methods coupled with individual differences and myths on the use of oral contraceptives. Some claimed pills would cause them to over bleed and may become barren.

Bilateral tubal ligation (BLT) was not utilized both before and after our intervention due to the low number of staff to offer the service. The fear of unstable families and gender-based violence that men may not allow them to use the method or women may be chased from their homes and fear of remarriages with no children after the new marriage furthermore contributed to the low utilization of
BTL. The lack of facilitation for the medical personnel to perform BTLs at the nearest health Centre further explains the low numbers of BTLs.

There were no vasectomies that had been carried out despite our intervention of increasing knowledge, probably due to a low male turn up, the males' misconception that they may lose their sexual prowess, both sexes knew family planning as a program majorly for women.

Depo was most used before and during our project implementation mainly because; 
- It was the most readily available method at the hospital and the health Centre VI.

- It does not need an extra skill to administer, being administered by any trained medical personnel.

- The community had more knowledge and experience about this method than any other method.

- The clients believed that the duration of a single shot is short-lived and could be easily given a try.

- Due to the male bias on family planning, women believed that it was easy to use since it could not be easily noticed by their husbands if there were no serious side effects like prolonged menstrual flows

There was low utilization of condoms by the participant because the condoms are distributed only at the health facility yet most men do not go to pick them and also due to the poor attitude of men towards FP. When we intervened by distributing condom boxes to the community members and the rest were given to the VHTs to make them readily available to the community. However, there were also misconceptions about condom use that is believed as being used by unfaithful partners and in prostitution.

\section{Conclusion}

\section{From the results of the project;}

- Increasing the knowledge of the people enhances family planning services utilization. This was evidenced by the increased utilization of the different FP methods which were lowly utilized initially.

- Increasing access to affordable family planning services is made possible by providing knowledge of the different facilities around providing FP services. This is evidenced by the increased number of people accessing FP services in Walukuba HC IV and JRRH

- Ensuring that women are educated about the various contraceptive methods gives them the chance to select their preferred method which limits the complaints since they are fully informed about the possible side effects and their management.

- Both utilization and awareness about different family planning methods improved but this result is also contributed to by the non-governmental organizations that provide family planning services in the district e.g. Marie Stopes international and UHMG.

\section{Lessons learnt}

1) Reaching out to community members is an effective means of creating a change in health practice.

2) Involving local authorities in the implementation of a community project makes it easier to mobilize the community members and improves their attitude towards the project.

3) Having a dedicated and hardworking project team simplifies the project implementation.

4) Involving the health facility especially the unit providing similar service make the work easy and gives ideas and even available resources which help make your work run smoothly

\section{Recommendations}

Despite the success of the project, there is still a lot of work needed to increase the knowledge and utilization of family planning services in the police wing village and Jinja district at large. The following are the recommendations to make this possible;

- Organize weekly health talks about family planning on media especially the local radio stations in Jinja district.

- Increase knowledge and change the attitude of the staff (technical) in the health facility on family planning, and increase knowledge on the management of side effects of FP methods amongst the staff at the health facility through CMEs.

- Organize training of staff on the provision of family planning services since this will enhance the utilization of the services.

- Promote and encourage male involvement in health services since this will reduce GBV linked to family planning.

- Put in practice protection of female rights to use family planning since this will boost their utilization.

- Giving/supplying condoms to the VHTs to aid in the distribution to the community members.

- Weekly health talks about contraceptive methods should be held in antenatal, postnatal, immunization, and ART clinics since this will enhance the knowledge and address their misconceptions about family planning.

\section{Limitations}

- Limited time available to carry out our project otherwise a larger number of people would be educated of the same 
- Transport to the venue where the health talks would be carried out posed a challenge as the funding was a bit expensive.

- We were unable to provide the community members with some refreshments during the sessions held due to insufficient funds.

- Scarcity of male partners to receive information about FP since the implementation was on a weekday and most of them were at their places of work.

- However, we are confident that the implemented project is significant and that the credibility and trustworthiness of the findings were enhanced by our multi-disciplinary, multi-lingual, and cooperative implementation team

\section{Acknowledgements}

Our COBERS has been a great success and has made a great impact on our education as medical students. The success is due to the contribution of many individuals whom we may not mention all, however, the following are worth mentioning

First and foremost, we would like to thank Makerere University College Of Health Sciences for organizing and funding the COBERS program which has allowed us as third-year students to learn about the community we would work within. The COBERS team most especially Mr. Oria Hussein (COBERS chairperson), Dr. Steven Kiwuwa, and his team at Child Health Development Centre (CHDC) for preparing us for our project implementation, orienting us, and giving us advice.

We would like to appreciate our University supervisor, Dr. Nakiyingi Lydia for guiding and taking responsibility for our COBERS activity. We appreciate our site tutor, Dr. Habyara Emmy for having made our stay at Jinja Regional Referral Hospital comfortable through the warm welcome, good guidance, and good care accorded to us during our stay here.

Especially we would like to thank the village health team Mrs. Joyce Mubekete for responding to every other call during which she was required to mobilize the community members and gather them at one place, other community leaders and members for their hospitality and kind information they gave us during our time of project implementation.

Lastly, special thanks go to the staff of Jinja Regional Referral Hospital staffs, especially the director Dr. Nkrunziza for welcoming us, all the staff of
JRRH for the knowledge and skills they have made us attain.

\section{Operational Definitions.}

Contraception; The use of various devices, chemical agents, sexual practices, or surgical procedures to prevent conception.

Maternal morbidity; Any condition that is attributed to or aggravated by pregnancy and childbirth that hurts the woman's wellbeing.

Maternal mortality; The death of a woman while pregnant or within 42 days of termination of pregnancy, from any cause related to or aggravated by the pregnancy or its management.

Unintended pregnancy; A pregnancy that an individual or couple did not plan to have, resulting in consensual or non-consensual intercourse.

Contraceptive; A device, sexual practice, or chemical agent that prevents pregnancy.

Family planning; The practice of timing, spacing, and limiting the number of children that are born using both natural (traditional) and modern (artificial) birth control methods. Family planning promotes the health of the mother, children, and the father.

\section{References:}

1) All Answers Ltd. (November 2018). Contraceptive Utilization and Sexual Practices of Female Undergraduate Students in University of Benin. Retrieved from https://ukdiss.com/examples/contrac eptive-utilization-sexual-practices.php?vref=1

2) Community diagnosis report of police wing village in walukuba east parish, Masese division,

3) Eliason S, Baiden F, Quansah-Asare G, GrahamHayfron Y, Bonsu D, Phillips J, Awusabo- Asare K. (2013) Factors influencing the intention of women in rural Ghana to adopt postpartum family planning. Reprod Health [Online]Available from: http://www.ncbi.nlm.nih.gov/pmc/articles/P MC3724747/[Accessed June 4, 2015]

4) Hubacher D, Mavranezouli I, McGinn E. (2008). Unintended pregnancy in sub-Saharan Africa: magnitude of the problem and potential role of contraceptive implants to alleviate it. Contraception. 78(1):73-78.

5) John G Cleland, Robert P Ndugwa \& Eliya M Zulu (2010). Family planning in sub-Saharan Africa: progress or stagnation? . WHO. https://www.who.i nt/bulletin/volumes/89/2/10-077925/en

6) Khan S., Bradley S., Fishel J., Mishra V. (2008) Unmet Need and the Demand for Family Planning in Uganda: Further Analysis of the Uganda Demo- 
graphic and Health Surveys, 1995- 2006.Calverton, MD, USA: Macro International Inc.;

7) Ministry of Health, Uganda. (2014). Uganda Family Planning Costed Implementation. Plan, 2015- 2020. Kampala: Ministry of Health, Uganda. Available from: https://www.healthpolicyproject.co $\mathrm{m} / \mathrm{ns} /$ docs/CIP_Uganda.pdf

8) Uganda Bureau of Statistics and MEASURE DHS/ICF international.(2016). Uganda Demographic and Health Survey 2016.Kampala, Uganda and Calverton, Maryland

9) United Nations (UN). Levels and Trends of Contraceptive Use as Assessed in 2002. New York, NY, USA: UN Department of Economic and Social Affairs; 2006:1-25.

10) United Nations Sustainable Developmental goals aka transforming our world; the 2030 agenda for sustainable development. 